\title{
Anti-Purkinje Cell and Natural Autoantibodies in a Group of Psychiatric Patients. Evidences for a Correlation with the Psychopathological Status
}

\author{
Roberto Delle Chiaie ${ }^{1,2}, *$, Brunella Caronti ${ }^{1,2}$, Francesco Macrì ${ }^{1}$, Sandra Campi ${ }^{1}$, Marzia Marino ${ }^{1}$, \\ Alessandra Corrado ${ }^{1}$, Maria Caredda ${ }^{1,2}$ and Massimo Biondi ${ }^{1,2}$
}

\author{
${ }^{I}$ Departement of Neurology and Psichiatry, "Sapienza" University of Rome, Italy \\ ${ }^{2}$ Policlinico Umberto-I Hospital, Rome, Italy
}

\begin{abstract}
Phenomena of autoimmunity are frequent among psychiatric patients, but we don't know yet if they should be considered primary and linked to the pathophisiology of the disorder, or aspecific and associated to a general immune system activation. Paraneoplastic Cerebellar Degeneration (PCD) represents a well known model of specific autoimmunity. In order to better understand the abovementioned issues, we used this condition to compare a set of immune dysfunctions found in a group of psychiatric patients. For this reason we tested sera from 48 psychiatric patients (24 schizophrenics, 17 bipolars and 7 obsessive-compulsive), 22 PCD patients and 52 healthy controls for the presence of anti-Purkinje autoantibodies and of some natural autoantibodies (ANAs, AMAs, APCAs, ASMAs). Psychopatological status of the psychiatric patients was assessed with BPRS, SANS, SAPS, HAM-D, CGI-S. In the psychiatric group anti-Purkinje autoantibodies were identified in 11/48 (22,9\%) patients, while they were present in 22/22 (100\%) PCD patients and in 0/52 (0\%) healthy controls. Among all anti-Purkinje autoantibody positive patients (in the PCD and psychiatric samples), only those belonging to the psychiatric sample, but not those with PCD, were frequently found positive also for natural autoantibodies, that are considered good markers of aspecific immune activation. In these patients, both anti-Purkinje and natural autoantibodies were found associated with acute/positive psychopathological symptoms. These results seem to point out that some phenomena of auto-immunity described in psychiatric patients could be aspecific, unrelated to the pathophysiology of the concomitant mental disorders and could be more frequent during phases of acute/positive symptoms.
\end{abstract}

Keywords: Anti-Purkinje autoantibodies, Bipolar Disorder, HPA Axis, Natural autoantibodies, Obsessive Compulsive Disorder, Paraneoplastic Cerebellar Degeneration, Schizophrenia.

\section{INTRODUCTION}

Evidence of the existence of a functional link between the CNS and the immune system come from the identification of a set of immune changes in various psychiatric disorders $[1,2]$. On the basis of these data, since among mental disorders schizophrenia has the least known etiology, most of the etiological hypotheses based on immunological mechanisms that have been advanced so far were formulated with reference to this illness [3-5]. Theories on autoimmune aspects of schizophrenia frequently invoke the notion of early infection by microorganisms possessing antigens that are so similar to CNS tissue, that resulting antibodies act against the brain $[6,7]$. However, should an immunological pathogenetic model of schizophrenia prove correct, the immune changes observed in this disorder should be strictly confined to these patients, while, if they are nonspecific, they should be considered unrelated to the underlying pathophysiology of schizophrenia and could therefore be present also in different psychiatric disorders. Several lines of evidence seem to confirm that immune changes so far identified

*Address correspondence to this author at the Dipartimento di Neurologia e Psichiatria, "Sapienza" Università di Roma, Via Leone IV 38, (00192) Roma, Italy; Tel: 06-39742364; Fax: 06-39038466;

E-mail: r.dellechiaie@centrokahlbaum.it in psychiatric patients are aspecific. Alpha-Interferon, an important mediator of autoimmune processes, induce several psychiatric adverse effects, like anxiety, depressive, manic and psychotic symptoms [8]. Different patterns of psychiatric symptoms were described also after administration of Lupus Anticoagulant (LA) and anticardiolipin antibodies (aCL) [9-11], thus confirming the possibility of an aspecific correlation between immune system dysfunctions and psychiatric symptoms. Therefore nonspecific factors, unrelated to the pathophysiology of underlying mental disorders, could trigger off immune system modifications in schizophrenia, as well as in other psychiatric conditions or in normals. Indeed several similarities beteween the immune system dysregulations observed in schizophrenia and those reported in affective disorders have so far been described, thus suggesting the possibility that they are aspecific and devoid of any etiological significance. The immune system dysfunctions reported in affective patients [12] seem connected to a functional activation of the hypothalamus-pituitary-adrenal (HPA) axis [13], therefore lacking of any etiological link with the onset of the illness [14]. Since conditions of functional activation of the HPA axis have been described also in other psychiatric conditions, including schizophrenia [15], this mechanism could be not considered strictly limited to affective disorders. Therefore, the immune dysfunctions so far identified in patients affected by different mental disorders could share a 
Table 1. Clinical and Demographic Charachteristics of the Psychiatric Patients (Group 1)

\begin{tabular}{|c|c|c|c|c|}
\hline Diagnosis & $\begin{array}{c}\text { Age } \\
\text { (Years) }\end{array}$ & Duration of Illness (Years) & $\begin{array}{c}\text { Duration of Therapy } \\
\text { (Years) }\end{array}$ & $\begin{array}{c}\text { Sex } \\
(\text { Males })\end{array}$ \\
\hline \hline Schizophrenia $\mathrm{n}=24$ & $\begin{array}{c}31.33 \\
\mathrm{SD}=8.25\end{array}$ & $\begin{array}{c}9.17 \\
\mathrm{SD}=5.33\end{array}$ & $\begin{array}{c}8.13 \\
\mathrm{SD}=4.98\end{array}$ & $23(95.83 \%)$ \\
\hline $\begin{array}{c}\text { Bipolar disorder } \\
\mathrm{n}=17\end{array}$ & $\begin{array}{c}45.23 \\
\mathrm{SD}=19.59\end{array}$ & $\begin{array}{c}7.83 \\
\mathrm{SD}=6.13\end{array}$ & $\begin{array}{c}7.00 \\
\mathrm{SD}=6.19\end{array}$ & $\begin{array}{c}11.50 \\
\mathrm{SD}=12.77\end{array}$ \\
\hline $\begin{array}{c}\mathrm{OCD} \\
\mathrm{n}=7\end{array}$ & $\begin{array}{c}12.16 \\
\mathrm{SD}=12.01\end{array}$ & $\mathrm{SD}=12.78$ & $\mathrm{p}=.424$ & $6(85.71 \%)$ \\
\hline $\mathrm{p}=.007$ & $\mathrm{p}=.394$ & $\mathrm{p}=.179$ \\
\hline
\end{tabular}

common underlying mechanism, disconfirming that those described in schizophrenia are pathogenetically linked with the onset of this disorder, as instead many authors frequently suggested [16-18].

To better understand the nature of the immune system disfunctions so far found in schizophrenia and in other mental disorders, we may compare immunological dysregulations described in these patients with those observable in autoimmune paraneoplastic syndromes. Indeed these disorders represent well studied models of specific autoimmunity triggered off by a reaction to precise classes of tumor antigens, to which compare other autoimmunological phenomenons whose specific nature remains to be proved (e.g. those observable in psychiatric patients). Among these syndromes, Paraneoplastic Cerebellar Degeneration (PCD) is a condition characterized by a pathogenetic process connected to the presence of anti-cerebellar seric autoantibodies [19]. In these cases, indirect immunofluorescence technique (IIF) detects the presence of autoantibodies reacting with the nucleus or cytoplasm of Purkinje cells and/or other cerebellar cytotypes [20], binding with clusters of ribosomes in the endoplasmic reticulum, on the trans-face of the Golgi apparatus or with nuclear antigens [21]. Antigenic proteins recognized by antiPurkinje antibodies are detectable in tumor tissues from these patients [19]. The presence of such a clear link between a specific tumor antigen, the production of an antitumor immune response, and the consequent detrimental effect on neural tissue make autoantibody-positive PCDs a very good reference model of specific autoimmunity to which compare other autoimmune phenomena in which the relation to the underlying pathogenetic process is less clear.

Based on this model, in order to improve our knowledge on differences and similarities of autoimmune phenomena present in PCD and in psychiatric patients, we compared the pattern of autoantibodies detectable with IIF technique in these two groups of patients and in a third group of normal healthy controls.

The first aim of this study was to observe if an antiPurkinje autoantibody, similar to that found in the specific autoimmune reaction of PCD, was detectable in a sample of psychiatric patients. The second objective was to investigate if this anti-Purkinje autoimmunity was or not confined to diagnostically homogeneous sub-groups of psychiatric patients. The last point was to clarify if intergroup differences in the frequency of other classes of autoantibodies, characteristic of nonspecific autoimmune reactions, could reveal a different nature of the immune process underlying the pres- ence of anti-Purkinje antibodies in PCD and psychiatric patients. The study was approved by the local ethical committee before its start.

\section{MATERIAL AND METHODS}

\section{Subjects}

One hundred and twenty-two caucasian subjects participated in the study. Subjects with a recent infectious process (such as common cold, angina or urinary tract infection) were excluded from this study. The experimental population was then divided into the following sub-groups:

1. Group 1 (Psychiatric patients). This was made up of 48 recently hospitalized patients meeting criteria for the following psychiatric disorders diagnosed according to DSM IV-TR (italian edition) criteria [22]: 24 with Schizophrenic Disorder (50\%), 17 with Bipolar Disorder (35\%) and 7 with Obsessive Compulsive Disorder (OCD) (15\%) (Table 1). Patients with substance abuse or organic mental disorders were excluded from the study. None of these patients presented Axis-1 or Axis-2 comorbidities. All these subjects were somatically healthy as screened with physical examination, complete blood count with differentials, serum enzymes and metabolite screening, urine analysis and thyroid function tests and all of them were studied while under psychotropic medication. None of them showed neurological signs of cerebellar origin, or of cerebellar atrophy at Computed Tomographic (CT) scanning.

2. Group 2 (Paraneoplastic cerebellar degeneration patients). Blood samples from 150 patients with suspected PCD were screened at the outpatient and inpatient neurological facilities of Policlinico Umberto I Hospital (Rome). The clinical picture was characterized by symptoms of pancerebellar syndrome with subacute onset and progressive course. Of these patients, 22 were diagnosed as affected by autoantibodypositive PCD, as sera were positive for anti-Purkinje antibodies, detected with IIF method, a tissue proved diagnosis of underlying cancer was available (lung cancer $43 \%$; lymphoma $29 \%$; prostatic cancer $14 \%$; uterus carcinoma 14\%) and CT scanning showed diffused cerebellar atrophy with no evidence of cerebral, cerebellar or leptomeningeal metastases. All were free of somatic diseases other than PCD and of any form of clinically relevant mental illness. They were devoid of current and past history of mental disorders. 
3. Healthy controls (Group 3). This group was made up of 52 normal healthy volunteers. None of these normal controls was a regular drinker or had ever been on psychotropic drugs except benzodiazepines (but not for one month before blood sample drawing). All were free from somatic and mental illness.

All subjects in the three groups were screened for the presence of Axis-I mental disorders by a member of the research group with several years of clinical experience (RDC) by means of the Structured Clinical Interview for DSM Disorders (SCID) [23]. Before being enrolled, patients of the psychiatric and neurologic groups and healthy controls gave their informed consent to participate to this study.

\section{Detection of Autoantibodies}

After an overnight fast a 10 cc blood sample was drawn from a cubital forearm vein at the same time in the morning (9 a.m.) for all patients and control subjects. Blood samples were centrifugated at $3000 \mathrm{rpm}$ for $15^{\prime}$ at $4^{\circ} \mathrm{C}$ (Omnifuge 2.ORS, Heraeus, Germany) and sera obtained were immediately frozen and stored at $-80^{\circ} \mathrm{C}$. Sera from psychiatric, PCD patients and from healthy controls were then screened for anti-Purkinje and four other types of autoantibodies: antinuclear (ANAs), anti-mithocondrial (AMAs), anti-smooth muscle (ASMAs) and anti-gastric parietal cells (APCAs). The IIF was used and results were rated by a member of the research group (BC), who was blind of the clinical condition of the patients tested.

1. Cerebellar (Anti-Purkinje) autoantibody detection. All serum specimens were screened for anti-Purkinje autoantibodies at diluitions of 1:100 in phosphatebuffered saline (PBS, pH 7.2) using the method described by Moll [24]; those with positive results were retested at serial diluitions of up to 1:5000. Unfixed frozen snap sections (10 $\mu \mathrm{m}$ thick) of cerebellum were obtained from healthy Wistar rats (260-280 grams, Nossan, Italy). To reduce the nonspecific binding of seric antibodies, cerebellar sections were incubated for 20' with non immune goat serum (Sigma, St. Louis, MO, USA) 1:10 diluted in PBS at room temperature (RT). The sections were incubated for 30' with each serum for 1 hour at RT. After rinsing three times in PBS for 5', the sections were incubated with 1:50 diluted goat anti-human $\operatorname{IgG}(\mathrm{Fab}) 2$ and $\operatorname{IgM}(\mathrm{Fab}) 2$ monoclonal antibodies conjugated with fluorescein isothyocianate (FITC)(Sigma, St. Louis, MO, USA) respectively. After rinsing in PBS, the sections were mounted in glycerine/PBS $(50 \% / 50 \%)$ and observed using a fluorescence microscope with a FITC outfit (Leitz, Germany). As a negative control, sections were incubated with PBS alone. Sera were considered positive for presence of anti-Purkinje autoantibodies when fluorescence staining was present at a diluition of 1:500.

2. ANAs, AMAs, ASMAs, APCAs detection. Seric antibodies were detected using the specific kits provided by Kallestad (Chaska, MN, USA) containing reagents, negative and positive control sera and substrates (human epithelial HEp-2 cells and mouse kidney/stomach for detection of ANAs, AMAs, ASMAs and APCA $s$ ).
The IIF was performed according to Kallestad Company's instructions. Specific substrates were incubated with the sera (1:40 or 1:20 diluited in PBS for HEp-2 and kidney/stomach, respectively) for 20' at RT. After two washes in PBS for 10', anti-human IgG antibody FITC-conjugated was added for 20' at RT. Finally the slides, rinsed twice in PBS for 10', were mounted in glycerine/PBS $(50 \% / 50 \%)$ and observed using a fluorescence microscope with a FITC outfit (Leitz, Germany). A non-immune serum was used as negative control; anti-ANA, anti-AMA, anti ASMA and antiAPCA sera (included in the kits) were used as positive control sera.

\section{Psycopathological Assessment}

All psychiatric patients (Group 1), regardless of their diagnosis, underwent a psychopathological assessment performed with the following rating scales: Brief Psychiatric Rating Scale (BPRS) [25], Scale for the Assessment of Negative Symptoms (SANS) [26], Scale for the Assessment of Positive Symptoms (SAPS) [27], Hamilton Depression Rating Scale (HAM-D, 21 item version) [28], Clinical Global Improvement-Severity (CGI-S) [29]. Scores were based on patients' psychopathological condition observed by the investigators at the time of blood drawing.

\section{Data Evaluation and Statistical Analysis}

Statistical analysis included several comparison methods. Pearson's correlation coefficients were applied to all psychometric variables to single out potential confounding effects. Pearson's Chi Square was used to examine categorical data, applying Yate's correction were necessary. Group mean differences were checked by means of analysis of variance (ANOVA) or multivariate analysis of variance (MANOVA), homogeneity of variances was tested using the univariate Levene test and the multivariate Box M. Post-hoc analysis was carried out with the Scheffé test. The minimum level of significance was set at $\mathrm{p}<.05$.

\section{RESULTS}

The mean age of psychiatric patients (Group 1: $36.3 \pm 15.07)$ was lower if compared to both PCD patients (Group 2: $56.5 \pm 10.5)[\mathrm{F}(1 ; 68)=32,23 ; \mathrm{p}=0.001]$ and healthy controls (Group 3: 43.5 \pm 15.3$)[\mathrm{F}(1 ; 98)=5.61 ; \mathrm{p}<0.02]$. The age of PCD patients (Group 2) was higher compared to healthy controls (Group 3) $[\mathrm{F}(1 ; 72)=13.2 ; \mathrm{p}<0.001]$. In the psychiatric sample the number of male subjects was significantly higher than in the other two samples (psychiatric group: M 42, F 6; PCD patients: M 7, F 15; healthy controls: M 26, F 26; $\left.\chi^{2}=24.79 ; \mathrm{df}=2 ; \mathrm{p}<.0001\right)$.

\section{AUTO-IMMUNITY}

1. Anti-Purkinje autoantibodies. Positivity of seric IgG anti-Purkinje antibodies was observed in 11/48 (22.9\%) psychiatric patients (Group 1). In these cases a bright fluorescence of Purkinje cells was present (Fig. 1). Of these 11 psychiatric patients, 6/24 (25\%) had a diagnosis of Schizophrenic Disorder, 3/17 (17.6\%) of Bipolar Disorder and 2/7 (28.6\%) of OCD. Similar IIF positivity was observed using serum of $22 / 22$ patients $(100 \%)$ with anti-Purkinje antibody 

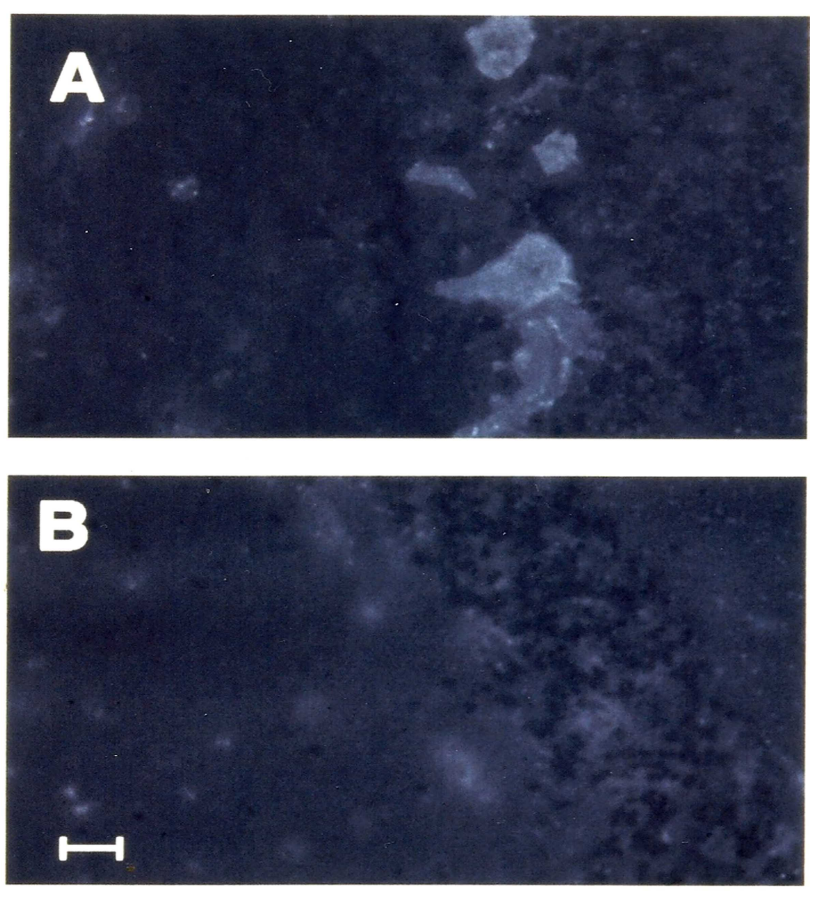

Fig. (1. a,b). Section of cerebellar cortex incubated with serum of a patient affected by schizophrenic disordered (dilution 1: 5,000) (a). Shown is granular fluorescence of Purkinje cell cytoplasm. Negative contro; (b) was performed replacing the serum PBS.

Calibration bar $=50 \mu \mathrm{m}$.

Table 2. Comparison of all the Clinical and Demographic Characteristics Between the Anti-Purkinje Autoantibody Positive and Negative Patients in the Psychiatric Group

\begin{tabular}{|c|c|c|c|c|c|c|c|c|c|c|c|c|c|c|c|c|c|}
\hline & Age & Dura- & & Sex & $\mathrm{BDZ}$ & NL & LITH- & TCA & CBZ & ECT & ANA & AMA & ASMA & APCA & \multicolumn{3}{|c|}{ Aris I dignosis } \\
\hline & Schizo & Bipolars & $O C D$ \\
\hline $\begin{array}{c}\text { Purkinje } \\
\text { Ab- } \\
\text { positive } \\
\mathrm{N}=11\end{array}$ & $\begin{array}{c}39.54 \\
\mathrm{SD}=17.63\end{array}$ & $\begin{array}{c}10.45 \\
S D=8.67\end{array}$ & $\begin{array}{c}8.88 \\
S D=4.22\end{array}$ & $\begin{array}{c}9 \\
(81.82 \%)\end{array}$ & $\begin{array}{c}5 \\
(45.45 \%)\end{array}$ & $\begin{array}{c}8 \\
(72.73 \%)\end{array}$ & $\begin{array}{c}2 \\
(18.18 \%)\end{array}$ & $\begin{array}{c}3 \\
(27.27 \%)\end{array}$ & $\begin{array}{c}5 \\
(45.45 \%)\end{array}$ & $\begin{array}{c}3 \\
(27.27 \%)\end{array}$ & $\begin{array}{c}0 \\
(0.00 \%)\end{array}$ & $\begin{array}{c}4 \\
(36.36 \%)\end{array}$ & $\begin{array}{c}6 \\
(54.55 \%)\end{array}$ & $\begin{array}{c}2 \\
(18.18 \%)\end{array}$ & $\begin{array}{c}6 \\
(54.55 \%)\end{array}$ & $\begin{array}{c}3 \\
(27.27 \%)\end{array}$ & $\left.\begin{array}{c}2 \\
(18.18 \%\end{array}\right)$ \\
\hline \multirow{2}{*}{$\begin{array}{c}\text { Purkinje } \\
\text { Ab- } \\
\text { negative } \\
N=37\end{array}$} & $\begin{array}{c}35.35 \\
\mathrm{SD}=14.35\end{array}$ & $\begin{array}{c}9.25 \\
\mathrm{SD}=7.51\end{array}$ & $\begin{array}{c}8.12 \\
S D=7.44\end{array}$ & $\begin{array}{c}33 \\
(89.19 \%)\end{array}$ & $\begin{array}{c}22 \\
(59.46 \%)\end{array}$ & $\begin{array}{c}23 \\
(62.16 \%)\end{array}$ & $\begin{array}{c}3 \\
(8.11 \%)\end{array}$ & $\begin{array}{c}16 \\
(43.24 \%)\end{array}$ & $\begin{array}{c}9 \\
(24.32 \%)\end{array}$ & $\begin{array}{c}7 \\
(18.92 \%)\end{array}$ & $\begin{array}{c}2 \\
(5.40 \%)\end{array}$ & $\begin{array}{c}5 \\
(13.51 \%)\end{array}$ & $\begin{array}{c}9 \\
(24.32 \%)\end{array}$ & $\begin{array}{c}4 \\
(10.81 \%)\end{array}$ & $\begin{array}{c}18 \\
(48.65 \%)\end{array}$ & $\begin{array}{c}14 \\
(37.84 \%)\end{array}$ & $\begin{array}{c}5 \\
(13.51 \%)\end{array}$ \\
\hline & $\mathrm{p}=.423$ & $\mathrm{p}=.661$ & $\mathrm{p}=.771$ & $\mathrm{p}=.896$ & $\mathrm{p}=.634$ & $\mathrm{p}=.776$ & $\mathrm{p}=690$ & $\mathrm{p}=548$ & $\mathrm{p}=.329$ & $\mathrm{p}=.860$ & $\mathrm{p}=.956$ & $\mathrm{p}=.222$ & $\mathrm{p}=.141$ & $\mathrm{p}=.921$ & & & $p=.797$ \\
\hline
\end{tabular}

positive PCD associated with an underlying neoplasm (Group 2), while 0/52 (0\%) healthy volunteers (Group 3 ) showed this positive finding. Negative control and sera of all healthy donors gave similar negative IIF results. Demographic variables (sex, age) of group 1 patients were analyzed, together with other clinical data (Axis I diagnosis, years of therapy, type of therapy), to find differences between the two sub-groups of the psychiatric sample (anti-Purkinje positive vs. negative) (See Table 2). Abovementioned analysis did not reveal any significative difference for such variables in these two subgroups.

2. ANAs, AMAs, ASMAs and APCAs. When we compared the frequency of ANAs, AMAs, ASMAs and APCAs in the 3 groups, ANAs were found positive in $2 / 48(4.2 \%)$ subjects of the psychiatric group (Group 1), while AMAs were detected in 9/48 (18.7\%), ASMAs in $15 / 48(31.3 \%)$ and APCAs in $6 / 48(12.5 \%)$.
No subject in the normal control group (Group 3) was found positive for seric ANAs, AMAs and APCAs, while in $2 / 52(3.9 \%)$ cases in this group were found positive for ASMAs. In 2/22 (9.1\%) patients with anti-Purkinje antibody positive PCD (Group 2), the presence of seric ASMAs was detectable, while ANAs, AMAs and APCAs were never identified. The frequency of anti-Purkinje autoantibodies $\left(\chi^{2}\right.$ $=79,02 ; \mathrm{df}=2 ; \mathrm{p}<.001)$, of AMAs $\left(\chi^{2}=15.31 ; \mathrm{df}=2\right.$; $\mathrm{p}<.00047), \operatorname{ASMAs}\left(\chi^{2}=15.58 ; \mathrm{df}=2 ; \mathrm{p}<.00041\right)$ and APCAs $\left(\chi^{2}=9.94 ; \mathrm{df}=2 ; \mathrm{p}<.0069\right)$ varied significantly in the three samples: they were more frequently observed in the psychiatric patient sample. The frequency of all the "natural" autoantibodies studied (ANAs, AMAs, ASMAs, APCAs) did not show any significant intergroup difference in the two subgroups of psychiatric patients (anti Purkinje antibody-positive vs. anti Purkinje antibody-negative) (see Table 2). 
Table 3. Comparison of the Psychometric Characteristics of the Two Sub-Groups of Psychiatric Patients (Purkinje-Ab Positive vs. Purkinje-Ab Negative)

\begin{tabular}{|c|c|c|c|c|}
\hline & \multicolumn{2}{|c|}{ Purkinje-Ab Positive n=11 } & \multicolumn{2}{|c|}{ Purkinje-Ab Negative $n=37$} \\
\hline & Mean & Std. Dev. & Mean & Std. Dev. \\
\hline SANS total & 38.36 & 29.80 & 43.78 & 19.55 \\
\hline SANS1 & 11.64 & 9.80 & 12.69 & 7.58 \\
\hline SANS2 & 6.73 & 6.62 & 7.61 & 4.88 \\
\hline SANS3 & 7.45 & 4.95 & 8.33 & 3.92 \\
\hline SANS4 & 9.91 & 7.69 & 12.64 & 5.54 \\
\hline SANS5 & 2.64 & 3.85 & 2.50 & 3.04 \\
\hline SAPS total $*$ & 37.64 & 21.51 & 19.06 & 14.29 \\
\hline SAPS1* & 6.09 & 4.91 & 3.14 & 3.81 \\
\hline SAPS2* & 8.36 & 5.46 & 4.67 & 4.55 \\
\hline SAPS3* & 11.55 & 5.07 & 4.56 & 3.51 \\
\hline SAPS4* & 11.64 & 8.82 & 6.69 & 6.07 \\
\hline HAMD* & 10.64 & 6.73 & 18.47 & 10.71 \\
\hline BPRS total & 34.00 & 7.89 & 36.08 & 11.48 \\
\hline Thougth disorder & 7.09 & 2.30 & 5.47 & 4.14 \\
\hline Interpersonal disturbance & 8.27 & 3.00 & 6.56 & 2.78 \\
\hline Retardation* & 5.55 & 2.66 & 8.00 & 2.59 \\
\hline Depression anxiety & 13.09 & 4.55 & 15.86 & 5.53 \\
\hline CGI-S & 5.36 & .67 & 4.97 & .97 \\
\hline
\end{tabular}

$* \mathrm{P}<.05$

\section{PSYCHOPATHOLOGICAL RATINGS}

1. Correlation to anti-Purkinje autoimmunity. The psychopathological status of anti-Purkinje positive and negative subgroups is shown in Table 3. Patients of the positive subgroup did not differ significantly from those of the negative one in global psychopatology measures such as CGI-S $[\mathrm{F}(1 ; 45)=1.548 ; \mathrm{p}=.219]$ and BPRS $[\mathrm{F}(1 ; 45)=.31 ; \mathrm{p}=.57]$. Differences in the psychopathological status of anti-Purkinje positive and negative psychiatric patients, independently of axis I diagnosis, were studied comparing all the values scored in the various rating scales. These variables were not significantly related to each other (Pearson's correlation matrix), thus indicating that they represented qualitatively different psychopathological indexes. A one-way MANOVA showed, globally, a significative intergroup difference for all the rating scale scores [Wilk's Lambda $=.704$; Rao's R (4; 42) $=4.412 ; \mathrm{p}=.004]$. Post-hoc analysis (Scheffè Test) showed that these differences were explained by SAPS-tot (anti-Purkinje positive $=37.64 \pm 21.51$; antiPurkinje negative $=19.06 \pm 14.29 ; \mathrm{p}=.001$ ) and HAM$\mathrm{D}$ (anti-Purkinje positive $=10.64 \pm 6.73$; anti-Purkinje negative $=18.47 \pm 10.71 ; \mathrm{p}=.027$ ) scores. This shows that anti-Purkinje positive psychiatric patients, regardless of their diagnosis, scored higher in the scales for the assessment of positive symptoms, whereas they scored lower on depression. However we may hy- pothesize that the lower HAM-D score found in this sample of anti-Purkinje autoantibody positive psychiatric patients with mixed diagnosis, besides depression itself, could be associated to the dimension of negative symptoms as well. In fact, although the global score of the BPRS in the post-hoc analysis did not distinguish Anti-Purkinje autoantibody positive and negative patients, the comparison (one-way ANOVA) of the BPRS sub-scores showed that the "retardation" sub-score was significantly lower in positive ones $[\mathrm{F}(1 ; 45)=7.496 ; \mathrm{p}=.008]$. Therefore, in our psychiatric group, symptoms assessed by HAMD, as also observed by other authors [30], could also overlap with the domain of negative symptomatology. Given that the presence of the anti-Purkinje autoantibodies was found associated, regardless of patient's diagnosis, to a clinical picture dominated by activating symptoms (measurable with the SAPS), we verified which of the 4 SAPS factors significantly influenced the difference observed in the 2 sub-groups (anti-Purkinje positive $v s$. anti-Purkinje negative) with regard to the total score of the scale. To this end, a one-way (anti-Purkinje antibody) ANOVA was carried out, and showed (see Table 3) how the two subgroups differed in all the 4 sub-scores (1 hallucinations, 2 delusions, 3 bizzarre behavior, 4 thought disturbance) $(\mathrm{p}<.05)$.

2. Correlation to natural autoantibodies. The distribution of positivity to natural autoantibodies was inde- 
pendent of the presence of the anti-Purkinje autoantibodies (see Table 2). This may lead to presume that these two phenomenons of autoimmunity are linked to different mechanisms. Since ASMAs and AMAs were the most common antibodies in the psychiatric population (ASMAs and/or AMAs positive patients $\mathrm{n}=19 ; 39.6 \%$ ), we verified if the cluster of psychopathological symptoms distinguishing anti-Purkinje autoantibody positive and negative patients was also able to discriminate patients positive to these two autoantibodies. The two sub-groups so obtained (see Table 4), as previously shown with regard to antiPurkinje autoantibodies, did not present significant differences on global psychopathology measures (CGI-S and BPRS). However, comparison of the psychometric scale scores of ASMAs and/or AMAs positive $v s$. negative patients with a one-way MANOVA, showed significant differences in these 2 subgroups [Wilks' Lambda=.766; Rao's R (4; 42)=3.207; p= .021], (Box $\left.\mathrm{M}=18.260 ; \chi^{2}=16.418 ; \mathrm{df}=10 ; \mathrm{p}=.088\right)$, that, according to post-hoc analysis, showed to depend on the difference in the SAPS total score. With a one-way ANOVA we observed significative intergroup difference in scores of all the 4 SAPS subscales. This comparison was carried out after having excluded any possible interference of other nonspecific factors (sex, diagnosis, drugs taken, age, years of illness, years of therapy). Therefore the psychopathological symptoms of patients positive for ASMAs and/or AMAs proved very similar to those which identify anti-Purkinje autoantibody positive patients.

\section{DISCUSSION}

The results of this study can be summarized as follows:

1. In a group of psychiatric patients with different diagnoses, we identified autoantibodies directed against the Purkinje neuron, similar to those which may normally be detected in a neurologic autoimmune disorder characterized by a highly specific pathogenetic mechanism (PCD).

2. While in PCD patients the presence of anti-Purkinje autoantibodies appears as a single immunological finding, among psychiatric patients those who were positive for anti-Purkinje antibodies, besides this organ specific autoantibody, were also positive for one or more other autoantibodies.

3. Psychiatric patients who were positive for antiPurkinje autoantibody and for the other phenomena of autoimmunity, more frequently had acute clinical presentations with prevalent positive symptoms and/or agitation.

This study has several important methodological limitations and its results should therefore be treated with caution. First of all psychiatric patients were diagnostically inhomogeneous and the sample size was too small to allow wide generalizations of the results. Furthermore the cross sectional design of the study does not support any inference on the possibility that the autoimmune findings could precede or follow the onset of psychiatric symptoms. For all these rea- sons further studies on this topic, performed on larger study populations and carried out with different methodologies are recommended. However, to the best of our knowledge, this is the first study to report in psychiatric patients the presence of anti-Purkinje autoantibodies, similar to those detectable in PCD. We believe that this finding is not fortuitous. In fact, even if the frequency of nonspecific phenomenona of autoimmunity increases with age $[31,32]$ and is higher in women [33], our psychiatric group was characterized by a lower mean age with respect to that of PCD patients and of the normal controls, and by an higher frequency of male subjects. This reduces the possibilities that the phenomena of autoimmunity that we reported in our psychiatric sample could have been influenced by nonspecific factors such as age and gender. Also psychotropic treatments, which often have been found nonspecifically associated with autoimmunity in psychiatric patients [34-36], in our study were not related to the presence of the anti-Purkinje autoantibody nor to natural autoantibodies as well. This suggests that probably the autoimmune phenomena observed in our sample of psychiatric patients were related only to the presence of a mental disorder. In neurological patients with PCD, since the autoantibody production derives from a specific pathogenetic mechanism based on the cross-reaction of antibodies directed against tumoral antigens with the Purkinje neurons, phenomenona of immune activation not strictly linked to this mechanism should not be expected. Conversely they may be present when organ-specific autoantibodies origin from different pathogenetic mechanisms. Our data seem to suggest that the anti-Purkinje autoantibodies observed in our sample of psychiatric patients and those of PCD patients are probably derived from different underlying mechanisms. In fact only psychiatric patients showed higher frequencies also for the other autoantibodies under investigation (ANAs, ASMAs, APCAs, AMAs), thus confirming that only in this group the positivity of the anti-Purkinje autoantibody, when present, was not a single autoimmune phenomenon. These other autoantibodies are considered to belong to the pool of the "natural" autoantibodies [37] that, contrary to antiPurkinje autoantibodies, are normally present in a certain percentage of healthy subjects. All adult organisms possess a limited number of B limphocytes carrying low affinity (a characteristic representing a functional mechanism protecting the self) $\operatorname{IgM}$ or IgG polyreactive autoantibodies as receptors. Although clone selection eliminates many autoreactive clones, some of these may remain. The autoimmune phenomena recorded in our psychiatric patients could be the result of autoantibodies of this origin, that in conditions of activation of the immune system, provide a rapid response to any exogenous or endogenous non-self agent, thus reaching concentrations that make them measurable. In fact, the synthesis of natural autoantibodies is based mainly on the activity of the of B CD5+ limphocytes subpopulation [38], that some authors have observed to increase in groups of psychiatric patients [39]. In our psychiatric group, the greater frequency of natural autoantibodies could represent a result of this mechanism. In anti-Purkinje autoantibody positive psychiatric patients, the origin of this organ-specific autoantibody could therefore be considered as a part of a vast and aspecific autoimmune activation, which is not based to any mechanism of immune cross-reaction comparable to that described in PCD patients. 
Table 4. Comparison of the Psychometric Characteristics of the Two Sub-Groups of Psychiatric Patients (AMA and/or ASMA Positive vs. AMA and/or ASMA Negative)

\begin{tabular}{|c|c|c|c|c|}
\hline & \multicolumn{2}{|c|}{ AMA and/or ASMA-Positive n=19 } & \multicolumn{2}{|c|}{ AMA and/or ASMA - Negative $n=29$} \\
\hline & Mean & Std. Dev. & Mean & Std. Dev. \\
\hline SANS total & 44.47 & 25.05 & 41.18 & 20.27 \\
\hline SANS2 & 8.05 & 6.45 & 6.96 & 4.38 \\
\hline SANS3 & 8.47 & 4.44 & 7.89 & 3.99 \\
\hline SAPS total $*$ & 33.21 & 18.55 & 16.75 & 14.16 \\
\hline SAPS1* & 5.63 & 4.97 & 2.61 & 3.19 \\
\hline SAPS2* & 8.26 & 4.81 & 3.68 & 4.24 \\
\hline SAPS3* & 8.26 & 5.57 & 4.79 & 3.87 \\
\hline Interpersonal disturbance & 7.21 & 3.33 & 6.79 & 2.62 \\
\hline Retardation & 7.16 & 3.15 & 7.61 & 2.54 \\
\hline Depression anxiety & 15.16 & 4.99 & 15.25 & 5.75 \\
\hline CGI-S & 5.11 & .81 & 5.04 & 1.00 \\
\hline
\end{tabular}

$* \mathrm{P}<.05$

Immune system activation was shown in patients with major depression to be connected to a functional dysregulation of the HPA axis [13]. However, this condition is not strictly confined to affective disorders, but seems to involve a wider group of psychiatric patients, psychotic or not, often characterized by acute presentations, frequently associated with symptoms of agitation [40]. Therefore many immune system dysfunctions present in psychiatric patients belonging to different diagnostic areas, could share this common underlying functional mechainism.

The autoimmune phenomena we reported were not confined to a specific diagnostic subgroup of psychiatric patients, thus suggesting the absence of any correlation with the pathophysiology of their mental disorders. Independently of their diagnosis, in our psychiatric sample those patients who were positive for the anti-Purkinje autoantibody showed a more pronounced symptom profile of activation. This was also observed in the subgroup of ASMAs and/or AMAs positive psychiatric patients (the two most common natural autoantibodies), so that it may be hypothesised that both anti-Purkinje and natural antibodies, independently of the psychiatric diagnoses of the patients, could be linked to common mechanisms.

The presence of similar findings of autoimmunity, such as autoantibodies against neurotransmitter receptors [41] or against serotonin [42], in psychiatric patients with different diagnoses was also reported in other studies. The possibility that these autoimmunological findings could correlate with acute psychopathological symptoms of activation was hypothesized by Haggerty [43] in a study on anti-thyroid autoimmunity performed on affective and non affective patients, and by Kim [44] in a study on autoantibodies to heat-shock proteins performed in patients with schizophrenia. This was also suggested by the data reported by Levy-Soussan et al. [45], who described that in a group of schizophrenic patients the presence of natural autoantibodies, similar to those measured in our study, showed an inverse correlation with the severity of negative symptoms. The possibility that the autoantibodies reported in schizophrenic patients, without being linked with the pathophysiology of this disorder, may be aspecifically linked to a general activation of the immune system, specially in presence of psychopathological symptoms of activation, has arised also from the results of other studies. Inglot et al. [46] reported increased levels of interferone in schizophrenic patients with positive symptoms, while reduced interferone levels were found in those with prevalent negative symptoms. Achiron et al. [47] observed a reduction in CD-4 2H4+ (suppressor-inducer) and CD-8 $2 \mathrm{H} 4+$ (suppressor-effector) lymphocytes in schizophrenic patients during acute phases of the illness. The same mechanism is also present in patients with autoimmune pathologies, and can lead to the activation of clones of autoreactive $\mathrm{T}$ and B lymphocytes. Increased IL-6 serum levels, an important stimulant of immune system and antibodies production, have been reported by several authors mainly in schizophrenic patients with poor therapy outcome [48]. The same conclusion was also suggested by Müller et al. [49]. These immunological dysfunctions did not correlate with the severity of psychotic symptoms, but were found associated with the presence symptoms of and activation and/or psychomotor agitation.

Signs of immunological activation observable during the acute phases of schizophrenic relapses are not only confined to peripheral blood, since increases of interleukin-2 levels (a 
citokine which promotes and mantains the immune responses) have also been reported in CSF of schizophrenics in association with recurrence of acute psychotic symptoms [50]. Enhanced levels of these cytokines may lead to autoimmunity, since this finding is also present in autoimmune disorders such as systemic lupus erithematosus [51].

On the whole these reports suggest that schizophrenic patients, at least in some phases of the illness, may present an immune system activation to which some phenomena of autoimmunity could be linked. The pathophysiology which underlies these phenomena could be very similar to that described for similar findings of autoimmunity described in patients with affective disorders. This could partially explain the lack of homogeneity that characterizes the results of the studies so far performed on the autoimmune phenomena of schizophrenic patients, that could reflect the lack of homogeneity in the psychopathological status of the patients evaluated. This could be the case for some studies in which negative findings of autoimmunity were reported [52-54], since the authors studied inhomogeneous experimental samples, that were made up indifferently of patients in an acute phase or in remission. This could represent a source of bias, since the diagnostic homogeneity does not necessarily correspond to a functional homogeneity of the mechanisms underlying immune system activation. Variations in immune system functional parameters have in fact been reported during the course of schizophrenia $[55,56]$. Whereas, when the inclusion of patients was based on the presence of acute psychotic symptoms, rather than on criteria of diagnostic homogeneity, both schizophrenic and affective patients showed the same signs of immune activation $[57,58]$. Therefore during the acute phases of schizophrenia these signs, which may be similar to those described in affective patients [59-70], could foster autoimmune phenomena according to mechanisms similar to those described for affective disorders [71]. Since these signs of immune system activation are probably linked to a functional disinhibition of the HPA axis, which may be considered a part of the stress response, similar autoimmune phenomena could be detected also in non-psychotic psychiatric patients, in which similar dysregulations of this neuroendocrine axis have sometimes been described [72, 73]. We observed the presence of the anti-Purkinje autoantibody also in a subgroup of OCD patients of our psychiatric sample. In a study on OCD patients, Maes [74] observed a positive correlation between the plasma levels of IL-6 and the severity of OCD symptoms, as well as a negative correlation between sIL-2R and cortisol plasma levels. The presence of immune alterations in non-psychotic psychiatric patients was also reported in studies on panic disorder, in which patients presented higher IL-1ß plasma levels [75] or changes in $\mathrm{T}$ and $\mathrm{B}$ cells and modified lymphocyte proliferative responses to mitogens $[76,77]$. These data seem to suggest a unitary nature of many immune phenomena detected in psychiatric patients. In fact most of these, both in affective and schizophrenic patients, have been considered consequent to an increased secretion of interleukins [13, 78, 79]. The production of both IL-1 [80] and IL-6 [81] is also controlled by circulating adrenaline, thus suggesting that stress may affect in this way several aspects of immunity. These mechanisms also explain the stimulatory role of the sympatho-adrenal system on the primary antibody response, re- ported in rats exposed to an experimental stress condition $[82,83]$. With regard to our study, autoimmune findings observed in our group of psychiatric patients, independently of their diagnoses, could be aspecific and linked to the high levels of stress associated to the presence of psychopathological activation. These symptoms, which often underlie the presence of a functional up-regulation of the HPA axis and of the sympatho-adrenal system, may therefore more frequently induce an immune system activation and lead to autoimmune phenomena.

Albeit its methodological shortcomings and limitations, we think that the results of this study nonetheless may suggest that many of the autoimmune findings so far observed in samples of psychiatric patients could be unrelated to the pathogenesis of their mental disorders, disconfirming several auto-immune pathogenetic models often argued by several authors, specially in the field of schizophrenia [18, 84-86]. This conclusions however need to be confirmed by further investigations.

\section{CONFLICT OF INTEREST}

The authors confirm that this article content has no conflicts of interest.

\section{ACKNOWLEDGEMENT}

Declared none.

\section{REFERENCES}

[1] Kapadia M, Sakic B. Autoimmune and inflammatory mechanisms of CNS damage. Prog Neurobiol 2011; 95(3): 301-33.

[2] Agius MA, Glasg FRCP, Arnason BGW. Autoimmune neurological disesases and their potential relevance to Psychiatry diseases. In: Gorman JM, Kertzner RM, Eds. Psychoimmunology Update. Washington DC: Am Psychiatry Press 1991; pp. 9-29.

[3] Müller N, Ackenheil M. The immune system and schizophrenia. In: Leonard BE, Miller K, Eds. Stress, the immune system and psychiatry. New York: John Wiley \& Sons 1995; pp. 137-64.

[4] Pendey RS, Gupta AK, Chaturvedy JC. Autoimmune model of schizophrenia with special reference to antibrain autoantibodies. Biol Psychiatry 1981; 16:1123-36.

[5] Caggiano MA, Alexander RC. The continued search for evidence of retroviral infection in schizophrenic patients. Schizophr Res 1991; 5: 243-7.

[6] Swedo SE, Leonard HL, Garvey M, et al. Pediatric autoimmune neuropsychiatric disorders associated with streptococcal infections: clinical description of the first 50 cases. Am J Psychiatry 1998; 155: 264-71.

[7] Strous RD, Shoenfeld Y. Schizophrenia, autoimmunity and immune system dysregulation: a comprehensive model updated and revisited. J Autoimmun 2006; 27: 71-80.

[8] Debien C, De Chouly De Lenclave MB, Foutrein P, Bailly D. Alpha-interferon and mental disorders. Encephale 2001; 27(4): 30817.

[9] Schwartz M, Rochus M, Weller B, et al. High association of anticardiolipin antibodies with psychosis. J Clin Psychiatry 1998; 59: 20-3.

[10] Chengappa KN, Carpenter AB, Keshaven MS, et al. Elevated IgG and IgM anticardiolipin antibodies in a subgroup of medicated and unmedicated schizophrenic patients. Biol Psychiatry 1991; 30: 7315 .

[11] Sokol DK, O'Brien RS, Wagenknecht DR, Rao T, McIntyre JA. Antiphospholipid antibodies in blood and cerebrospinal fluids of patients with psychosis. J Neuroimmunol 2007; 190: 151 - 6.

[12] Leonard BE. Stress and the immune system: immunological aspects of depressive illness. In: Leonard BE, Miller K, Eds. Stress, the immune system and psychiatry. New York: John Wiley \& Sons 1995; pp. 113-36. 
[13] Maes M, Sharpé S, Meltzer HY, et al. Relationship between Interleukin-6 activity, acute phase proteins, and function of the hypothalamic-pituitary-Adrenal axis in severe depression. Psychiatry Res 1993; 49:11-27.

[14] Perantie DC, Brown ES. Corticosteroids, immune suppression, and psychosis. Curr Psychiatry Rep 2002; 4(3): 171-6.

[15] Arana GW, Barriera PJ, Cohen BM, et al. The dexametasone suppression test in psychotic disorders. Am J Psychiatry 1983; 140:1521-3.

[16] Knight DJ, Cooper SJ. Viruses, immunity and mental disorder. Br J Psychiatry 1989; 154: 1-7.

[17] Eaton William W, Pedersen Marianne G, Nielsen Philip R, Mortensen Preben BO. Autoimmune diseases, bipolar disorder, and nonaffective psychosis. Bipolar Disord 2010; 12(6): 638-46.

[18] Eaton WW, Byrne M, Ewald H, et al. Assdociation of schizophrenia and autoimmune diseases: linkage of Danish National Registers. Am J Psychiatry 2006; 163: 521-8.

[19] Posner JB, Furneaux HM. Paraneoplastic syndromes. In: Waksman $\mathrm{BH}$, Ed. Immunologic mechanisms in neurologic and Psychiatry disease. New York: Raven Press 1990; pp. 187-219.

[20] Rodriguez M, Trhu LI, O’Neil BP, Lennon VA. Autoimmune paraneoplastic cerebbellar degeneration: Ultrastructural localization of antibody-binding sites in Purkinje cells. Neurology 1988; 38: 1380-6.

[21] Jaeckle KA, Houghton AN, Nielsen SL, Posner JB. Demonstration of serum anti-Purkinje antibody in paraneoplastic cerebellar degeneration and preliminary antigenic characterization. Ann Neurol 1983; 14: 111

[22] Andreoli V, Cassano GB, Rossi R, Eds. American Psychiatry Association. DSM-IV-TR (Italian Edition: Manuale Diagnostico e Statistico dei Disturbi Mentali) Milano: Elsevier 2007.

[23] First MB, Spitzer RL, Gibbon M, Williams JBW. Structured Clinical Interview for DSM-IV Axis-I Disorders (SCID-I) Washington DC: Am Psychiatry Press 1994.

[24] Moll JWB, Henzen-Logmans SC, Vecht CHJ. Anti-neuronal antibodies in paraneoplastic neurological disorders with small cell lung carcinoma. Clin Neurol Neurosurg 1990; 92: 223-8.

[25] Overall JE, Gorham DR. The brief Psychiatry rating scale. Psychol Rep 1962; 10: 799-812.

[26] Andreasen NC. Negative symptoms in schizophrenia: definition and reliability. Arch Gen Psychiatry 1982; 39: 784-8.

[27] Andreasen NC, Olsen S. Negative vs positive schizophrenia: definition and validation. Arch Gen Psychiatry 1982; 39:789-4.

[28] Hamilton MA. A rating scale for depression. J Neurol Neurosurg Psychiatr 1960; 23: 56-62.

[29] Guy W. ECDEU Assessment Manual for psychopharmacology. Rockville (MD): U.S. Department of of Health and Human Services 1976; pp. 534-5.

[30] Zubin J. Negative symptoms: are they indigenous to schizophrenia? Schizophr Bull 1985; 11: 461-70.

[31] Manoussakis MN, Tzioufas AG, Silis MP, et al. High prevalence of anti-cardiolipin and other autoantibodies in healthy elerly patients. Clin Exp Immunol 1987; 69: 557-65.

[32] Delespesse G, Gausset P, Sarfati M, et al. Circulating immune complexes in old people and diabetics: correlation with autoantibodies. Clin Exp Immunol 1980; 40: 96-102.

[33] Turnbridge WMG, Evered DC, Hall R. The spectrum of thyroid disease in a community: the Whickaham survey. Clin Endocrinol 1977; 7: 481-92.

[34] Berglung S, Gottfries CG, Cottfries I, Stormby K. Chloropromazine-induced antinuclear factors. Acta Med Scand 1970; 187: 67-74.

[35] Canoso RT, Hutton RA, Deykin D. A chloropromazine-induced inhibitor of blood coagulation. Am J Haematol 1977; 2:183-91.

[36] Canoso RT, Lewis ME, Yunis EJ. Association of HLA-Bw44 with chloropromazine-induced autoantibodies. Clin Immunol Immunopathol 1982; 25: 278-82.

[37] Avrameas S. Natural autoantibodies: from "horror autotoxicus" to "gnothi seauton". Immunol Today 1991; 12: 154-9.

[38] Casali P, Notkins AL. CD5 ${ }^{+}$B lymphocytes, polyreactive antibodies and the human B-cell repertorie. Immunol Today 1989; 10: 364-8.

[39] McAllister CG, Rapaport MH, Pickar D, et al. Increased number of CD5+ B lymphocytes in schizophrenic patients. Arch Gen Psychiatry $1989 ; 46: 890-4$.

[40] Gastpar M, Gilsdorf U, Abou-Saleh MT, Ngo-Khac T. Clinical correlates of response to DST. J Affect Disord 1992; 26: 17-24.
[41] Tanaka S, Matsunaga H, Kimura M, et al. Autoantibodies against four kinds of neurotransmitter receptors in Psychiatry disorders. J Neuroimmunol 2003; 141: 155-64.

[42] Schott K, Schaefer JE, Richartz E, et al. Autoantibodies to serotonin in serum of patients with Psychiatry disorders. Psychiatry Res 2003; 121: 51-7.

[43] Haggerty JJ, Evans DL, Golden RN, et al. The presence of antithyroid antibodies in patients with affective and nonaffective Psychiatry disorders. Biol Psychiatry 1990; 27: 51-60.

[44] Kim JJ, Lee SJ, Toh KY, Lee CU, Lee C, Paik IH. Identification of antibodies to heat shock proteins $90 \mathrm{kDa}$ and $70 \mathrm{kDa}$ in patients with schozophrenia. Schizophr Res 2001; 52: 127-35.

[45] Levy-Soussan P, Barbouche R, Porier MF, Galinowski A, Loo H, Avrameas S. A preliminary prospective study on natural autoantibodies and the response of untreated schizophrenic patients to neuroleptics. Biol Psychiatry 1994; 35: 135-8.

[46] Inglot AD, Leszek J, Piasecki E, Sypula A. Interferon responses in schizophrenia and major depressive disorders. Biol Psychiatry 1994; 35: 464-73.

[47] Achiron A, Noy S, Pras E, Lereya J, Hermesh H, Laor N. T-cell subset in acute psychotic schizophrenic patients. Biol Psychiatry 1994; 35: 27-31.

[48] Schwarz M, Müller N, Riedel M, Ackenheil M. The Th-2hypothesis of schizophrenia: a strategy to identify a subgroup of schizophrenia caused by immune mechanisms. Med Hypotheses 2001; 56: 483 - 6.

[49] Müller N, Ackeneheil M, Hofschuster E, Mempel W, Eckstein R. Cellular immunity in schizophrenic patients before and during neuroleptic treatment. Psychiatry Res 1991; 37: 147-60.

[50] McAllister CG, van Kammen DP, Rhen TJ, et al. Increases in CSF levels of interleukin-2 in schizophrenia: effects of recurrence of psychosis and medication status. Am J Psychiatry 1995; 152: 12917.

[51] Huang YP, Perrin LH, Miescher PA, Zubler RH. Correlation of T and $B$ cell activities in vitro and serum IL-2 levels in systemic lupus erythematosus. J Immunol 1988; 141: 827-33.

[52] Plioplys A, Thibault J, Bouchard JP, Clockburn C, Hawakes R. Anti-CNS antibodies in neurological and Psychiatry disorders. J Neurol Neurosurg Psychiatr 1987; 5: 1514-21.

[53] Galinowski A, Barbouche R, Truffinet P, et al. Natural autoantibodies in schizophrenia. Acta Psychiatr Scand 1992; 85: 240-2.

[54] McDaniel JS, Jewart RD, Eccard MB, et al. Natural killer cell activity in schizophrenia and schizoaffective disorder: a pilot study. Schizophr Res 1992; 8: 125-8.

[55] Masserini C, Vita A, Basile R, et al. Lymphocyte subsets in schizophrenic disorder. Schizophr Res 1990; 3: 269-75.

[56] Sasaki T, Nanko S, Fukuda R, Kawate T, Kunugi H, Kazamatsuri $\mathrm{H}$. Changes of immunological functions after acute exacerbations in schizophrenia. Biol Psychiatry 1994; 35: 173-8.

[57] Srikanth S, Ravi V, Shenoy Poornima K, Shetty KT, Gangadhar $\mathrm{BN}$, Janakiramaiah N. Viral antibodies in recent onset, nonorganic psychoses: correspondence with symptomatic severity. Biol Psychiatry 1994; 46: 517-21.

[58] Ohaeri JU, Hedo CC, Lagundoye OO. The profile of C-reactive proteins in functional psychotic states in a cohort in Nigeria. Acta Psychiatr Scand 1993; 88: 252-5.

[59] Müller N, Ackenheil M, Hofschuster E. Altered T-cell number and reduced suppressor cell activity in patients with affective psychosis. In: Hadden JW, Masek K, Nistico G, Eds. Interactions among central nervous system, neuroendocrine and immune systems. Rome: Pythagora Press 1989; pp. 385-94.

[60] Müller N, Hofschuster E, Ackenheil M, Mempel W, Eckstein R. Investigation of the cellular immunity during depression and the free interval: Evidence for an immune activation in affective psychosis. Prog Neuropsychopharmacol Biol Psychiatry 1993; 48: 201-17.

[61] Maes M, Bosmans E, Suy E, Vandervorst C, Dejonckheere C, Raus J. Antiphospholipid, antinuclear, Epstein-Barr and cytomegalovirus antibodies, and soluble interleukin-2 receptors in depressive patients. J Affect Disord 1991; 21:133-40.

[62] Maes M, Lambrechts J, Bosmans, et al. Evidence for a systemic immune activation during depression: Results of leucocyte enumeration by flow cytometry in conjunction with monoclonal antibody staining. Psychol Med 1992; 22: 45-53. 
[63] Maes M, Van der Planken M, Stevens W, et al. Leukocytosis, monocytosis and neutrophilia: Hallmarks of severe depression. $\mathbf{J}$ Psychiatr Res 1992; 2: 125-34.

[64] Maes M, Stevens W, DeClerk L, et al. A significantly increased number and percentage of B cells in depressed subjects: Results of flow cytometric measurements. J Affect Disord 1992; 24: 127-34.

[65] Maes M, Scharpé S, Bosmans E, et al. Disturbances in acute phase plasma proteins during melancholia: Additional evidence for the presence of an inflamatory process during that illness. Prog Neuropsychopharmacol Biol Psychiatry 1992; 16: 501-15.

[66] Maes M, Stevens W, DeClerk L, et al. A significantly increased expression of T-cell activation markers in depression: Additional evidence for an inflamatory process during that illness. Prog Neuropsychopharmacol Biol Psychiatry 1993; 17: 214-25.

[67] Nassberger L, Träskman-Bendz L. Increased soluble interleukin-2 receptor concentrations in suicide attempters. Acta Psychiatr Scand 1993; 88: 48-52.

[68] Joyce PR, Hawes CR, Mulder RT, Sellman JD, Wilson DA, Boswell DR. Elevated levels of acute plasma proteins in major depression. Biol Psychiatry 1992; 32: 1035-41.

[69] Deberdt R, Van Hooren J, Biesbrouk M, Amery W. Antinuclear factor positivity in mental depression: A single disease entity? Biol Psychiat ric 1976; 11: 27-31.

[70] Gastpar M, Müller W. Autoantibodies in affective disorders. Prog Neuropsychopharmacol 1981; 5: 91-6.

[71] Maes M, Meltzer HY, Jacobs J, et al. Autoimmunity in depression: increased antiphospholipid autoantibodies. Acta Psychiatr Scand 1993; 87: 160-6.

[72] Abou-Saleh MT. Dexamethasone suppression test in psychiatry: Is there a place for an integrated hypothesis? Psychiatr Dev 1985; 3 : 275-306.

[73] Mellsop GW, Hutton JD, Delahunt JW. Dexamethasone suppression test as a simple measure of stress? Br Med J 1985; 290: 18046.

[74] Maes M, Meltzer HY, Bosmans E. Psychoimmune investigation in Obsessive Compulsive Disorder: assay of plasma transferrin, IL-2 and IL- 6 receptor, and IL- $1 \beta$ and IL- 6 concentrations. Neuropsychobiology 1994; 30: 57-60.
[75] Brambilla F, Bellodi L, Perna G, Bertani A, Panerai A, Sacerdote P. Plasma interleukin-1 Beta concentrations in panic disorder. Psychiatry Res 1994; 54: 135-42.

[76] Marazziti D, Ambrogi F, Vanacore R. Immune cell imbalance in major depressive and panic patients. Neuropsychobiology 1992; 26: $23-6$.

[77] Brambilla F, Bellodi L, Perna G, et al. Psychoneuroendocrine aspects of panic disorder. Neuropsychobiology 1992; 26: 12-22.

[78] Maes M, Bosmans E, Meltzer HY, Sharpé S, Suy E. Interleukin-1B: a putative mediator of HPA axis hyperactivity in major depression. Am J Psychiatry 1993; 150: 1189-93.

[79] Rapaport MH, McCallister CG. Neuroimmunological factors in schizophrenia. In: Gorman JM, Kertzner RM, Eds. Psychoimmunology Update. Washington DC: Am Psychiatry Press 1991; pp. 31-47.

[80] Dobbin JP, Harth M, McCain GA, Martin RA, Cousin K. Cytokine production and lymphocyte transformation during stress. Brain, Behav Immun 1991; 5: 339-48.

[81] DeRijk RH, Boelen A, Tilders FJH, Berkenbosch F. Induction of plasma interleukin- 6 by circulating adrenaline in the rat. Psychoneuroendocrinology 1994; 19: 155-63.

[82] Croiset G, Heijnen CJ, van der Wal WE, de Boer SF, De Wied D. A role for the autonomic nervous system in modulating the immune response during mild emotional stimuli. Life Sci 1990; 46: 419-25.

[83] Nunes SOV. An autoimmune or an inflammatory process in patients with schizophrenia, schizoaffective disorder, and in their biological relatives. Schizophr Res 2006; 84: 180 - 2.

[84] Henneberg HA, Horter S, Ruffert S. Increased prevalence of antibrain antibodies in the sera from schizophrenic patients. Schizophr Res 1994; 14: 15-22.

[85] Kilidireas K, Latov N, Strauss DH, et al. Antibodies to the human $60 \mathrm{kDa}$ heat shock protein in patients with schizophrenia. Lancet 1992; 340: 569-72.

[86] Alrot V, Rothermund M, Peters M, Leonard B. Immunological reasearch in clinical psychiatry: report on the consensus debite durino the 7th export meeting on psychiatry and immunology. Mol Psychiatry 2002; 7: 822-6.

Received: April 17, 2012

Revised: May 02, 2012

Accepted: May 04, 2012

(c) Delle Chiaie et al.; Licensee Bentham Open.

This is an open access article licensed under the terms of the Creative Commons Attribution Non-Commercial License (http://creativecommons.org/licenses/by-nc/3.0/) which permits unrestricted, non-commercial use, distribution and reproduction in any medium, provided the work is properly cited. 